\title{
Effect of Body Weight-supported Walking on Exercise Capacity and Walking Speed in Patients with Knee Os- teoarthritis: A Randomized Controlled Trial
}

\author{
Shinichi Watanabe, $\mathrm{PT}^{1,2}$ and Fujiko SomeYa, $\mathrm{MD}, \mathrm{PhD}^{3}$ \\ 1) Graduate School of Medical Science, Division of Health Sciences, Graduate Course of Rehabilitation Science, Kanazawa University: \\ 5-11-80 Kodatsuno, Kanazawa, Ishikawa 920-0942, Japan \\ 2) Department of Rehabilitation Medicine, Nanao Hospital, National Hospital Organization: 3-1 Matto, Nanao, Ishikawa 920-8531, \\ Japan \\ 3) Pharmaceutical and Health Sciences, School of Health Sciences, College of Medical, Kanazawa University: 5-11-80 Kodatsuno, Ka- \\ nazawa, Ishikawa 920-0942, Japan
}

\begin{abstract}
Objective: To compare the effect of body-weight-supported treadmill training (BWSTT) and full-body-weight treadmill training (FBWTT) on patients with knee osteoarthritis (OA). Methods: Design was Randomized controlled trial. Patients with knee osteoarthritis $(n=30$; mean age, $76.0 \pm 7.5$ y) were randomly assigned to BWSTT or FBWTT group. All patients performed 20 min walking exercise twice a week for 6 weeks under the supervision of the therapist. Main measures were 10-meter walking test (10MWT), functional reach test (FRT), timed get up and go test (TUG), one-leg standing test, 6-minute walking test (6MWT), the parameters set on the treadmill, MOS Short-Form 36-Item Health Survey (SF36), Japanese Knee Osteoarthritis Measure (JKOM). Results: Twenty-five patients (10 men, 15 women; mean age, $76.5 \pm$ 8.0 y) completed the experiment. Exercise capacity, indicated by the heart rate, was similar in both groups. After 3 weeks of BWSTT, the patients performed significantly better in the 10-m and 6-min walking tests. This was not the case with FBWTT even after 6 weeks training. Pain levels assessed were significantly improved after 3 weeks of BWSTT and 6 weeks of FBWTT. There were no significant improvements in either group assessed by the FRT, one-leg standing time test, TUG, or SF -36 questionnaire. Conclusions: BWSTT enhanced exercise capacity in terms of walking speed and pain reduction after 3 weeks; however, there was no significant improvement in patients' functional abilities or quality of life.
\end{abstract}

Key words: Aerobic exercise, knee pain, Knee osteoarthritis, walking

(J Jpn Phys Ther Assoc 16: 28-35, 2013)

$\mathbf{O}$ steoarthritis (OA) is the most typical disease involving joint deformity. The American Academy of Orthopedic Surgeons (AAOS) proposes that aerobic exercise is highly efficacious in reducing the pain associated with OA of the knee. The range of strategies that may relieve pain and disability include motion exercise, balance exercise, physical medical treatments, manipulation therapy and acupuncture.

Received: January 6, 2013

Accepted: May 21, 2013

Advance Publication by J-STAGE: June 28, 2013

Correspondence to: Shinichi Watanabe, Graduate School of Medical Science, Division of Health Sciences, Graduate Course of Rehabilitation Science, Kanazawa University: 5-11-80 Kodatsuno, Kanazawa, Ishikawa 920-0942, Japan

e-mail: billabonghonor@yahoo.co.jp
About the effectiveness of aerobic exercise in patients with knee OA, the American Academy of Orthopaedic Surgeons: A meta-analysis ${ }^{1,2)}$ and AAOS of guidelines ${ }^{3)}$, exercise therapy with respect to effects on physical function in patients with knee OA is strong evidence has been shown. In a study conducted by Ettinger et al. . $^{4}$ the study patients with knee OA were classified into 3 groups; a walking exercise group and two groups of muscular power reinforcement movement. There was a significant improvement seen in both the groups after the intervention 15 months.

Hootmen et al. ${ }^{5)}$ reported that high-intensity, high-impact activity may increase the risk of trauma or knee OA. Moderate intensity walking exercise might be appropriate and convincing for patients with arthritis.

Body-weight-supported treadmill training (BWSTT) 
has recently been proposed as a therapy for patients with walking disorders. Improvements have been observed in walking speed and the distance that patients are able to walk among patients with spinal cord injury ${ }^{6,7)}$, stroke ${ }^{8-11)}$, cerebral palsy $^{12)}$, and Parkinson's disease ${ }^{13,14)}$, in response to BWSTT. Patients who have undergone orthopedic surgery are reported to have greater walking speed, stride, and relief from symptoms when performing the 10-meter walking test (10MWT) immediately after BWSTT ${ }^{15)}$. In a randomized controlled trial of patients who had undergone total hip arthroplasty, BWSTT was significantly associated with pain relief and greater endurance during walking ${ }^{16)}$. Advantages of BWSTT are the convenience of walking, lesser risk of falling while using harness, better walking speed, and the amount of load can adjusted according to the patient's potential. Canal there advantages suggest a possibility that a BWSTT might be useful as a patients with knee OA walking exercise. The benefits of BWSTT have not yet been studied among patients with knee OA who have not previously undergone surgery. In this study we aimed to compare the effects of BWSTT and full-body-weight treadmill training (FBWTT) in terms of their walking speed, exercise capacity, self-reported symptoms, and health related quality of life. The purpose of this RCT was to assess if BWSTT can be useful in a attaining a faster walking speed, increase the exercise capacity, retains the self-conscious condition a walk, and if health related quality of life improves when compared with the usual treadmill walk.

\section{Methods}

The patients in our study and who were diagnosed with knee OA to the outpatient clinic of the Department of Rehabilitation, National Hospital Organization, Nanao Hospital., between June 2010 and June 2011. Inclusion criteria for knee osteoarthritis patients were: (1) ability to understand and follow commands; (2) no medical contraindication to walking; (3) ability to walk independently; (4) Not received artificial joint replacement therapy in the past. The patients were allocated by a computer-generated random sequence provided by a researcher not involved in the enrolment process. One group of patients was assigned to undergo 6 weeks of BWSTT, and the other to 6 weeks of FBWTT. During the study period, no patients received exercise therapy other than that provided as the study intervention. None of the patients included in the study had a history of sharp leg pain while at rest, and all of them were able to walk independently without a cane. Moreover, the grade classification (Yokohama city classification) by a load X-rays front image and the Japan Orthopedic Association (JOA) score were estimated those with knee OA, disease severity was evaluated using the Yokohama City Classification system and JOA score by consultation at a family doctor. The Yokohama City Classification system was classified into three groups of grade 1 (Bone sclerosis or osteophyte formation), grade 2 (Narrowing of joint space $\leq 3 \mathrm{~mm}$ ), and grade 3 (Obliteration of joint space or subluxation $)^{17)}$. JOA score is used in the clinical evaluation of orthopedic patients and consists of four categories: pain and stair-climbing ability, range of motion, and joint swelling. A maximum score of 100 indicates a normal knee joint $^{18)}$.

The study was approved by the Nanao hospital's ethics committee (approval number: 2002 01-05). We explained the purpose of study to the patients and they gave their written consent to participate.

\section{Treadmill Training Protocol}

During BWSTT, the patients were partially suspended by a harness, which was part of the Biodex body weight support unit (Biodex, BDX UWSZ). The support unit comprised a vest that covered the patient's trunk to the level of the thighs, and this was connected to the harness by means of a wire suspension system. As the amount of body weight support varied according to body sway during walking, we monitored the range of support and adjusted the median of the range to $20 \%$ of the patient's body weight. The treadmill speed was set by the patients themselves: those in the BWSTT group were instructed to walk as fast as possible and those in the FBWTT group were asked to walk at their usual speed. BWSTT has been reported to decrease the energy consumption ${ }^{19)}$; therefore, it set to the walking rate quicker than FBWTT. We followed the guidelines of the American Geriatrics Society ${ }^{20)}$ to determine the intensity, time and frequency of exercise was set at low to moderate, that is, between $40 \%$ and $60 \%$ of the maximum heart rate, from 12 to 14 of ratings of perceived exertion. In addition, each subject was shown the 15 point Borg Rating of Perceived Exertion scale and instructed in its use. The Rating of Perceived Exertion scale was mounted on the wall in front of the treadmill and easily visible to the subjects. Measurement of cardiac beats rate used the heart rate meter (Poral RS100) by making a maximum heart rate into 220age. These criteria provided the appropriate intensity for aerobic exercise. Patients exercised for a total of $20 \mathrm{~min}$ per day; the exercise duration was chosen to minimize the risk of patients needing to rest due to fatigue. There was no patient who stopped movement within 10 minutes of exercise. Additionally, there was no patient who gave the reason for rest, reported fatigue or breathlessness while undergoing this test.

The exercise was conducted twice a week for 6 weeks. Both groups performed stretching for $5 \mathrm{~min}$ and slow walking for $3 \mathrm{~min}$ as a warm-up exercise before the intervention. Any patient who suffered leg pain that became worse during or after exercise was assessed by the doctor after the intervention. In the stretch, it carried out similarly to all the subjects to quadriceps femoris and the ham string. 
In the warm-up, it enforced for 3 minutes at the speed of $1 \mathrm{~km} / \mathrm{h}$. Previous studies reported ${ }^{8,10,11,13-16)}$ that BWSTT is effective when its level accounts for 15 to $50 \%$ of the body weight; within the range, we employed $20 \%$ for the present study, which had been the upper limit of BWS levels with harnesses being most unlikely to deviate in a preliminary experiment.

\section{Outcome Measures}

Patients were physically evaluated before the intervention (baseline), and after 3 and 6 weeks of the intervention. Patients were assessed on the day of training. The evaluation included the $10-\mathrm{m}$ walking test $(10 \mathrm{MWT})^{21)}$, functional reach test $(\mathrm{FRT})^{22)}$, one-leg standing test ${ }^{23)}$, timed get up and go test $(\mathrm{TUG})^{24)}, 6$-min walking test $(6 \mathrm{MWT})^{25)}$, and the parameters set on the treadmill ${ }^{26}$. We used the Medical Outcomes Study Short-Form 36-Item Health Survey version $2.0(\mathrm{SF}-36)^{27)}$ and the Japanese Knee Osteoarthritis Measure $(\mathrm{JKOM})^{28)}$ to evaluate health-related quality of life. JKOM has 25 questions about "pain and stiffness in knees", "condition in daily life", " general actives", " health conditions" with 5 classifications per category and the assessment of knee pain by means of a visual analog scale (VAS). For FBWTT, we computed walking speed, distance and the mean and variability of stride length while walking at a comfortable speed for 6 min using the analyzer (Biodex, BDX UWS2). The walk for 6 minutes was measured using analysis equipment and each average value was computed.
Both groups performed this evaluation on the comfortable speed conditions in full weight load. In addition, the heart rate was monitored every minute during exercise. A therapist, who was blinded to the exercise strategies, evaluated these physical functions throughout the study.

\section{Statistical Analysis}

Two-way analysis of variance was performed with both exercise groups and the evaluation time points (baseline, 3 weeks and 6 weeks) as independent variables. The dependent variables were the values obtained from the physical function tests, the walking speed, distance covered, and stride length during treadmill walking, and the date from SF-36 and JKOM. We subsequently performed post hoc analysis using the Bonferroni correction for multiple comparisons. We used the unpaired from of the t-test the mean heart rate during training in both exercise groups for every 5 minute of training time. We used JMP8.0 for analysis and the threshold for statistical significance was set to $<5 \%$.

\section{Results}

A total of 37 patients with knee OA were included in this study based on the inclusion criteria. Seven of them were excluded from the study as they did not match the inclusion criteria. The study comprised of 9 men and 21 women, with an average age of $76 \pm 7.5$ years (mean \pm SD). Twelve patients in the FBWTT groups ( 5 men and 7

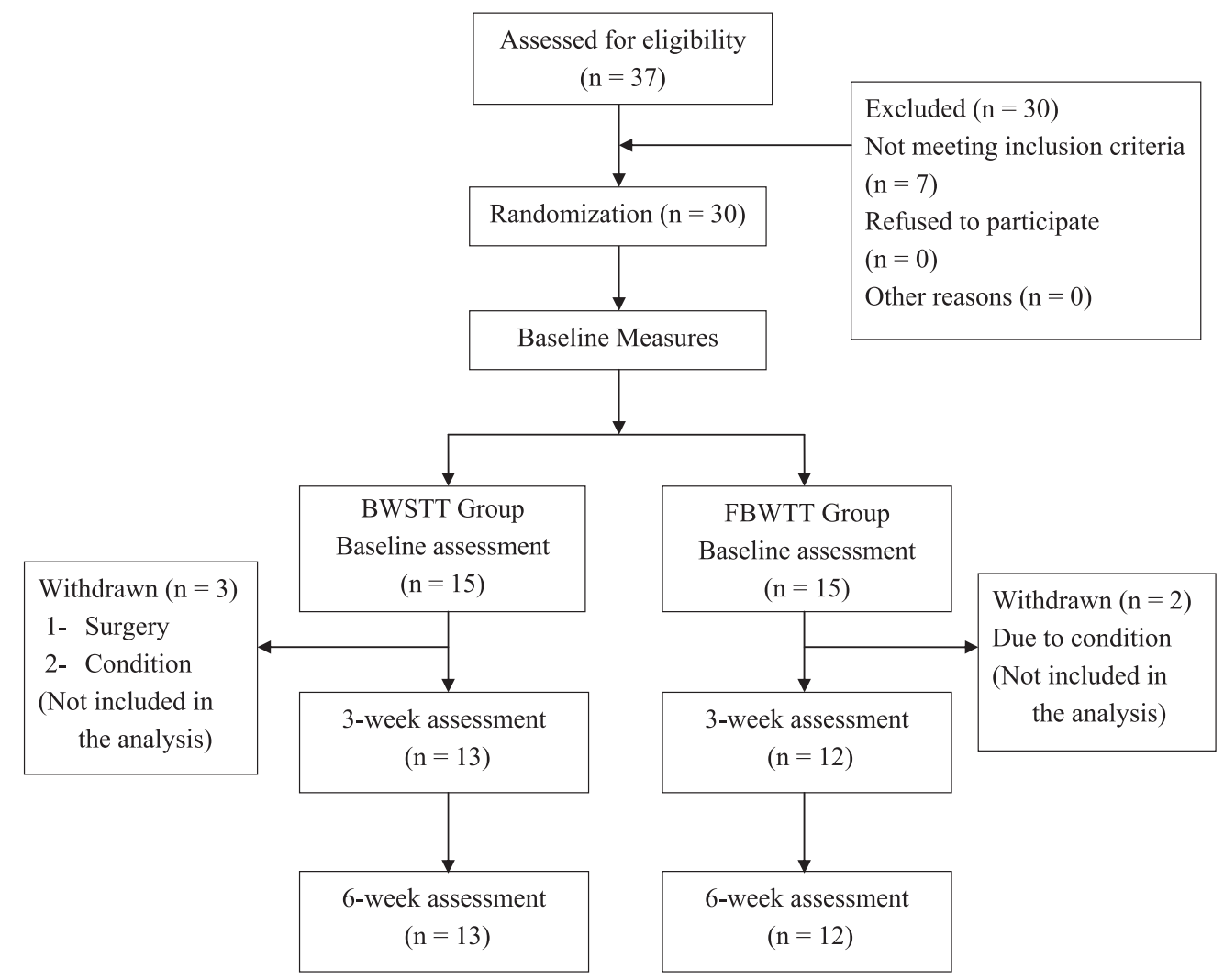

Fig. 1. Flowchart showing the numbers of patients included and excluded at different stages of the study 
Table 1. Characteristic of the Study Participants

\begin{tabular}{lccc}
\hline Characteristics & FBWTT $(\mathrm{n}=15)$ & BWSTT $(\mathrm{n}=15)$ & $\mathrm{p}$ \\
\hline Age $(\mathrm{y})$ & $75 \pm 7.6$ & $80.0 \pm 5.9$ & $0.68^{\mathrm{b}}$ \\
Sex $(\mathrm{M} / \mathrm{F})$ & $5 / 10$ & $4 / 11$ & $0.69^{\mathrm{a}}$ \\
Height $(\mathrm{cm})$ & $156.2 \pm 12.1$ & $154.8 \pm 12.6$ & $0.22^{\mathrm{b}}$ \\
Weight $(\mathrm{kg})$ & $55.4 \pm 8.4$ & $53.2 \pm 9.1$ & $0.41^{\mathrm{b}}$ \\
BMI $\left(\mathrm{kg} / \mathrm{m}^{2}\right)$ & $22.7 \pm 3.1$ & $22.2 \pm 3.7$ & $0.32^{\mathrm{b}}$ \\
Affected side (Left/Right) & $12 / 3$ & $11 / 4$ & $0.66^{\mathrm{a}}$ \\
X-P Grade & I: 5, II: 14, III: 10 & I: 4, II: 15, III: 8 & $0.86^{\mathrm{c}}$ \\
& $(15$ patients, 29 knees $)$ & $(15$ patients, 27 knees $)$ & \\
\hline
\end{tabular}

Values are represented as mean $\pm \mathrm{SD}$ or $\mathrm{n}$ under $* \mathrm{p}<0.05$.

a: Chi- square test , b: t-test, c: Mann-Whitney U test

F, female; M, male; BMI, body mass index

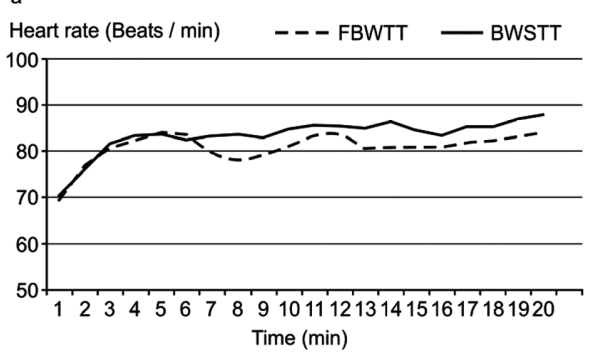

c

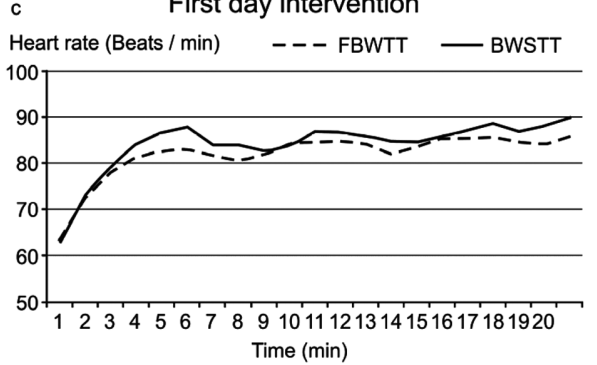

After 6-week intervention

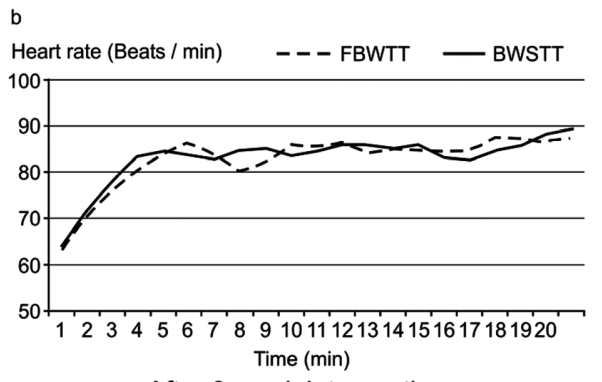

After 3-week intervention

Fig. 2. Changer in heart rate during treadmill training

The values are presented as the mean heart in each group on day 1 (a), and after 3 (b) and 6 (c) weeks of the intervention. The dotted line represents the FBWTT group $(n=12)$ and the solid line represents the BWSTT group $(\mathrm{n}=13)$. There were no significant differences between the group (one-way analysis of variance).

women) and 13 patients in the BWSTT group ( 5 men and 8 women) completed 6 weeks of the exercise intervention (Fig. 1, Table 1). Five patients dropped out of the study as they were hospitalized, developed cold, or refused to undergo re-evaluation. There were no significant differences in the profiles of the two groups in terms of age, sex, height, weight, body mass index, side affected reported due to OA, $\mathrm{X}-\mathrm{P}$ grade classification, or JOA score.

The mean heart rates (HR) during walking exercises were did not differ significantly between the 2 groups (Fig. 2 ). HR indicated the exercise intensity was aerobic. In the physical function test (Table 2), statistical interactions were observed in the length of time taken for the 10MWT and the 6MWT. There were no significant differences between groups in the results of the FRT, the one-leg standing test, the TUG or the parameters set on the treadmill. However, there were statistical interactions for using the Analyzer in walking speed, distance, and stride length variability (Table 3 ). Stride length variability was also greater after 6 weeks for FBWTT, but there were no significant differences between groups. Responses to questions in the SF-36 did not differ significantly between groups, including those related to pain (Table 4). Pain and stiffness in the knees assessed by the JKOM were improved after 6 weeks of exercise intervention in both groups (Table 5). Pain levels indicated by the visual analog scale were significantly reduced after training. The group with BWSTT showed significantly higher values than that with FBWTT in all study periods, 
Table 2. Physical functions of the study patients

\begin{tabular}{|c|c|c|c|c|c|}
\hline \multirow[t]{2}{*}{ Test } & \multirow[t]{2}{*}{ Group } & \multicolumn{3}{|c|}{ Time point } & \multirow[t]{2}{*}{ Interaction } \\
\hline & & Baseline & 3 Weeks & 6 Weeks & \\
\hline \multirow{2}{*}{$\begin{array}{c}10-\mathrm{m} \text { walk } \\
(\mathrm{s})\end{array}$} & FBWTT & $13.5 \pm 5.1$ & $12.5 \pm 4.6$ & $11.8 \pm 4.3$ & \multirow[t]{2}{*}{0.038} \\
\hline & BWSTT & $12.8 \pm 4.6$ & $10.5 \pm 3.2^{\#}$ & $8.9 \pm 2.4^{\#}$ & \\
\hline \multirow{2}{*}{$\begin{array}{l}\text { Stride length } \\
(\mathrm{cm})\end{array}$} & FBWTT & $50.3 \pm 11.1$ & $51.1 \pm 9.5$ & $52.6 \pm 10.3$ & \multirow[t]{2}{*}{0.645} \\
\hline & BWSTT & $49.6 \pm 11.3$ & $53.8 \pm 11.2$ & $56.7 \pm 10.9$ & \\
\hline \multirow{2}{*}{$\begin{array}{l}\text { functional reach } \\
\qquad(\mathrm{cm})\end{array}$} & FBWTT & $20.1 \pm 5.5$ & $22.0 \pm 5.2$ & $23.7 \pm 6.0$ & \multirow[t]{2}{*}{0.763} \\
\hline & BWSTT & $18.6 \pm 6.8$ & $19.6 \pm 6.2$ & $22.2 \pm 6.5$ & \\
\hline \multirow{2}{*}{$\begin{array}{l}\text { Right one-legged standing } \\
\text { (s) }\end{array}$} & FBWTT & $4.1 \pm 2.1$ & $4.1 \pm 2.2$ & $5.0 \pm 1.7$ & \multirow[t]{2}{*}{0.603} \\
\hline & BWSTT & $3.8 \pm 3.0$ & $4.7 \pm 3.9$ & $6.0 \pm 4.4$ & \\
\hline \multirow{2}{*}{$\begin{array}{l}\text { Left one-legged standing } \\
\text { (s) }\end{array}$} & FBWTT & $4.2 \pm 2.9$ & $5.3 \pm 3.0$ & $5.5 \pm 3.5$ & \multirow[t]{2}{*}{0.516} \\
\hline & BWSTT & $4.6 \pm 3.5$ & $4.9 \pm 3.4$ & $5.4 \pm 3.3$ & \\
\hline \multirow{2}{*}{$\begin{array}{l}\text { Timed get up and go } \\
(\mathrm{sec})\end{array}$} & FBWTT & $12.5 \pm 3.8$ & $12.0 \pm 3.7$ & $11.3 \pm 3.1$ & \multirow[t]{2}{*}{0.865} \\
\hline & BWSTT & $12.6 \pm 3.7$ & $11.0 \pm 2.9$ & $10.6 \pm 3.5$ & \\
\hline \multirow{2}{*}{$\begin{array}{l}\text { 6-min walking } \\
\text { (m) }\end{array}$} & FBWTT & $188.5 \pm 53.7$ & $191.9 \pm 44.2$ & $195.0 \pm 45.4$ & \multirow[t]{2}{*}{0.043} \\
\hline & BWSTT & $199.2 \pm 79.5$ & $234.7 \pm 81.4^{\#}$ & $262.0 \pm 90.1^{\#}$ & \\
\hline
\end{tabular}

Values are presented as mean $\pm \mathrm{SD} .{ }^{*} \mathrm{p}<0.05$ vs. baseline (Bonferroni); FBWTT, $\mathrm{n}=12$; BWSTT, $\mathrm{n}=13$

Table 3. Walking Speed, Distance, and Stride Length during Treadmill training

\begin{tabular}{clcccc}
\hline Parameter & Group & \multicolumn{3}{c}{ The point } & \multirow{2}{*}{ Interaction } \\
\cline { 3 - 4 } & & Baseline & 3 Weeks & 6 Weeks & \\
\hline Walking speed & FBWTT & $2.47 \pm 0.81$ & $2.58 \pm 0.92$ & $2.67 \pm 0.93$ & 0.028 \\
$(\mathrm{~km} / \mathrm{h})$ & BWSTT & $2.25 \pm 0.92$ & $2.52 \pm 0.69^{\#}$ & $2.82 \pm 0.63^{\# \S}$ & \\
\hline Distance & FBWTT & $235.41 \pm 91.1$ & $243.5 \pm 93.6$ & $251.6 \pm 99.0$ & 0.046 \\
$(\mathrm{~m})$ & BWSTT & $218.54 \pm 76.3$ & $240.0 \pm 67.7^{\#}$ & $266.8 \pm 64.8^{\# \S}$ & \\
\hline Right stride length & FBWTT & $38.5 \pm 8.3$ & $39.4 \pm 9.6$ & $40.8 \pm 9.3$ & 0.155 \\
$(\mathrm{~cm})$ & BWSTT & $42.6 \pm 10.5$ & $44.7 \pm 8.5$ & $47.4 \pm 7.2$ & 0.263 \\
\hline Left stride length & FBWTT & $39.4 \pm 9.0$ & $40.3 \pm 8.1$ & $41.9 \pm 8.2$ & 0.042 \\
$(\mathrm{~cm})$ & BWSTT & $42.3 \pm 8.4$ & $45.5 \pm 7.1$ & $47.5 \pm 6.4$ & \\
\hline Right stride length & FBWTT & $18.4 \pm 4.2$ & $16.4 \pm 3.5$ & $13.7 \pm 3.0^{\#}$ & 0.037 \\
variability (\%) & BWSTT & $23.5 \pm 9.4$ & $15.6 \pm 6.0^{\#}$ & $10.5 \pm 4.1^{\#}$ & \\
\hline Left stride length & FBWTT & $19.5 \pm 6.2$ & $19.0 \pm 5.6$ & $17.3 \pm 5.0$ & 0.0 \\
variability (\%) & BWSTT & $23.4 \pm 11.2$ & $17.8 \pm 11.8$ & $12.0 \pm 4.4^{\# \sharp \dagger}$ & \\
\hline
\end{tabular}

Values are represented as mean \pm SD. ${ }^{\#} \mathrm{p}<0.05$ vs. baseline (Bonferroni); ${ }^{\S} \mathrm{p}<0.05$ vs 3 week (Bonferroni)s; ${ }^{\dagger} \mathrm{p}<0.05$ vs FBWTT (Bonferroni), FBWTT, $\mathrm{n}=12$; BWSTT, $\mathrm{n}=13$

including the pre-intervention period.

\section{Discussion}

There were no differences between groups in heart rate during exercise, indicating that the intensity of the exercise was similar in both. The training load was set at the level of aerobic exercise, and pain relief assessed by the visual ana$\log$ scale was significantly improved within 3 weeks of the intervention. The patients treated with BWSTT could also correct the stride length variability, increase walking speed, and walk the longer distance, as seen in 3 weeks of inter- vention. These improvements in walking function were not found among the cases with FBWTT. Therefore, BWSTT was found to be beneficial in increasing the exercising capacity and walking speed with ameliorated pain in 3 weeks; however; no improvement was seen in balance function related to activities and general quality of life. The distance walked across the floor in the 6MWT was shorter than the distance covered on the treadmill over the same period of time (6-min). Walking on the treadmill feels faster and requires a greater number of steps compared to when walking on the flat ground ${ }^{29)}$. In patients who had undergone total hip arthroplasty, Hesse et al. ${ }^{16)}$ reported significantly increased 
Table 4. Short Form-36 Score

\begin{tabular}{|c|c|c|c|c|c|}
\hline \multirow[t]{2}{*}{ Parameter } & \multirow[t]{2}{*}{ Group } & \multicolumn{3}{|c|}{ Term } & \multirow[t]{2}{*}{ Interaction } \\
\hline & & Baseline & 3 Weeks & 6 Weeks & \\
\hline \multirow[t]{2}{*}{ Physical functioning } & FBWTT & $52.9 \pm 9.4$ & $56.0 \pm 14.0$ & $55.0 \pm 7.1$ & 0.888 \\
\hline & BWSTT & $53.8 \pm 7.1$ & $59.0 \pm 8.8$ & $58.0 \pm 6.7$ & \\
\hline \multirow[t]{2}{*}{ Role physical } & FBWTT & $56.3 \pm 14.6$ & $56.0 \pm 14.0$ & $56.0 \pm 14.0$ & 0.514 \\
\hline & BWSTT & $57.3 \pm 9.2$ & $59.0 \pm 8.7$ & $60.0 \pm 8.7$ & \\
\hline \multirow[t]{2}{*}{ Bodily pain } & FBWTT & $50.4 \pm 8.0$ & $51.5 \pm 7.3$ & $50.8 \pm 7.0$ & 0.767 \\
\hline & BWSTT & $52.9 \pm 8.5$ & $56.1 \pm 6.1$ & $56.1 \pm 6.8$ & \\
\hline \multirow[t]{2}{*}{ Social functioning } & FBWTT & $52.3 \pm 7.3$ & $53.3 \pm 9.6$ & $53.8 \pm 7.9$ & 0.317 \\
\hline & BWSTT & $53.2 \pm 9.1$ & $55.1 \pm 7.9$ & $57.1 \pm 8.0$ & \\
\hline \multirow[t]{2}{*}{ General health perceptions } & FBWTT & $48.8 \pm 7.7$ & $49.6 \pm 6.6$ & $49.6 \pm 5.0$ & 0.156 \\
\hline & BWSTT & $51.5 \pm 8.3$ & $52.7 \pm 7.0$ & $53.8 \pm 6.2$ & \\
\hline \multirow[t]{2}{*}{ Vitality } & FBWTT & $53.4 \pm 10.2$ & $53.4 \pm 10.2$ & $53.9 \pm 9.9$ & 0.449 \\
\hline & BWSTT & $55.8 \pm 8.0$ & $56.8 \pm 7.6$ & $56.8 \pm 7.6$ & \\
\hline \multirow[t]{2}{*}{ Role emotional } & FBWTT & $49.4 \pm 12.0$ & $50.9 \pm 10.3$ & $56.7 \pm 10.9$ & 0.980 \\
\hline & BWSTT & $55.2 \pm 8.7$ & $56.7 \pm 7.2$ & $56.7 \pm 7.2$ & \\
\hline \multirow[t]{2}{*}{ Mental health } & FBWTT & $48.8 \pm 6.8$ & $50.4 \pm 5.0$ & $51.3 \pm 4.3$ & 0.084 \\
\hline & BWSTT & $49.6 \pm 5.9$ & $50.8 \pm 5.3$ & $52.3 \pm 5.3$ & \\
\hline
\end{tabular}

Values are presented as mean score $\pm \mathrm{SD}$

FBWTT, $\mathrm{n}=12 ;$ BWSTT, $\mathrm{n}=13$

Table 5. Score Derived from the Japanese Knee Osteoarthritis

\begin{tabular}{lccccc}
\hline \multicolumn{1}{c}{ Parameter } & Group & \multicolumn{3}{c}{ Term } & \multirow{2}{*}{ Interaction } \\
\cline { 3 - 5 } & & Baseline & 3 Weeks & 6 Weeks & \\
\hline Pain and stiffness in knees & FBWTT & $19.0 \pm 2.7$ & $17.8 \pm 2.5$ & $16.3 \pm 1.9^{\#}$ & 0.214 \\
& BWSTT & $18.8 \pm 1.8$ & $16.9 \pm 1.7$ & $15.2 \pm 1.7^{\#}$ & \\
\hline Condition in daily life & FBWTT & $24.8 \pm 5.0$ & $23.8 \pm 5.4$ & $21.7 \pm 5.5$ & 0.718 \\
& BWSTT & $26.0 \pm 4.6$ & $23.6 \pm 5.1$ & $22.0 \pm 5.2$ & \\
\hline General activities & FBWTT & $13.2 \pm 4.3$ & $13.3 \pm 4.0$ & $12.8 \pm 4.2$ & 0602 \\
& BWSTT & $12.1 \pm 3.6$ & $11.3 \pm 3.4$ & $1.08 \pm 3.5$ & \\
\hline Health conditions & FBWTT & $6.2 \pm 1.2$ & $6.1 \pm 1.2$ & $5.8 \pm 1.3$ & 0.637 \\
& BWSTT & $6.3 \pm 1.2$ & $5.8 \pm 1.3$ & $5.6 \pm 1.2$ & \\
\hline VAS & FBWTT & $4.9 \pm 1.2$ & $4.8 \pm 0.8^{\#}$ & $4.3 \pm 0.9^{\#}$ & 0.162 \\
& BWSTT & $4.7 \pm 1.2$ & $3.9 \pm 0.7^{\#}$ & $3.6 \pm 0.7^{\#}$ & \\
\hline Total & FBWTT & $63.1 \pm 9.0$ & $60.9 \pm 8.4$ & $56.5 \pm 7.8$ & 0.966 \\
& BWSTT & $63.2 \pm 5.6$ & $57.7 \pm 5.7$ & $53.5 \pm 4.1$ & \\
\hline
\end{tabular}

Values are presented as mean score \pm SD except for the VAS, which is presented as length \pm SD; ${ }^{\#} \mathrm{p}<0.05$ vs. baseline (Bonferroni)

FBWTT, $\mathrm{n}=12$; BWSTT, $\mathrm{n}=13$

activity in the gluteus medius muscle during walking after 3 or 12 months of BWSTT compared to conservative physiotherapy; this resulted in pain relief and improvement in walking patterns. However the guidelines on knee OA have not referred to a change in the stride length variability by aerobic exercise; pain reduction might be able to induce the stride length variability change. Alternatively, there is a possibility that improved walking pattern during the intervention ameliorated the pain.
In a study of BWSTT patients with hip arthroplasty, a shortened stance phase has been observed with BWSTT, especially during the double stance phase ${ }^{16)}$. The authors suggest that the affected leg, which was too painful to support the patient's weight, was compensated by the suspension, so that stance phase could be extended and the patient could perform symmetrical walking. Three weeks of BWSTT significantly improved stride length in our study. These results are similar to the findings of the previous 
study which reported that the training not only corrected asymmetric walking pattern but also increased stride length and exercise capacity ${ }^{16}$. We found that within 3 weeks, BWSTT is generally safe with a low risk of falls, and is known to decrease the burden on the cardiopulmonary system ${ }^{30)}$. Thus, training with suspension could be performed at a faster speed than usual without suspension. These factors resulted in faster walking speeds with BWSTT but not with FBWTT.

The time patients took to complete 10 -and 6-m walking tests as also improved within 3 weeks of BWSTT only. As the assessment represents walking speed and exercise capacity, the mechanism of improvement would be the same as mentioned above.

There were no significant changes in either group in terms of data obtained from the SF-36, according to the JKOM and VAS, patients experienced significantly reduced pain and stiffness in the knees. As the SF-36 provides a nonspecific evaluation of general health, it might have limited sensitivity for assessing knee pain. In contrast, the JKOM is a disease specific tool for the evaluation of quality of life in knee OA, developed at the Western Ontario and McMaster Universities and adapted for a Japanese lifestyle. The JKOM has been shown to be reliable and valid of the accepted by the comparison examination with SF36 or Westren Ontario and McMaster Universities ${ }^{28)}$. The JKOM therefore, may be superior to the SF-36 in identifying pain reduction in patients with knee OA. No differences were noted in any item except pain between the 2 groups, possibly because the disease severity was relatively mild in many patients, and the intervention period was short (6 weeks) in this study.

Although an object disease differs from this research, Kamide et al. ${ }^{31)}$ reported that increased walking speed resulting from BWSTT did not contribute to balance function. Indeed, the results of the FRT, one-leg standing test and TUG, which represent balance function during ordinary activities, remained the same after the exercise intervention in this study.

\section{Study Limitations}

There are several limitations of this study. One of the limitations was its small sample size. Therefore, the results of present study may not be clinically relevant although they seemed to be a statistically significant. Another limitation was that the study was conducted for short period; therefore, generalization of these results was inconclusive unless further studies on long-term effect of body-weightsupported walking in patients with knee OA are performed. In the present study, we could not clarify the influence of knee osteoarthritis according to its severity. Also, those routinely using a cane were involved in the study as well, which is a potential selection bias. We did not use clinical results in this study. This was in order to suggest an improvement of the ambulatory ability in the patients with knee OA. Further, the present study was conducted in patients from a single facility; therefore, participants' selection might have local deviation. A detailed meta-analysis is required to generalize the findings of this research. One of the reasons for our result might be due to patients' impaired balance shown by the TUG and the FRT, which has been shown to be lower than that in the healthy communitydwelling elderly ${ }^{32,33)}$. It is possible that during the $6 \mathrm{MWT}$, the patients walked more slowly when they turned corners to avoid falling. It is not clear whether walking function on the treadmill accurately reflects walking on the ground. To demonstrate the practical effects of BWSTT, we need to analyze how treadmill walking relates to walking on the ground.

Colby et al ${ }^{19)}$ reported a decreased oxygen uptake during walking brace by weight. In present study, the walking speed was set to different conditions of equivalent energy consumption between the two groups. Therefore, the effect of BWSTT in this study was independent of the weight support as the difference in walking speed could not be defined clearly.

\section{Conclusions}

After 3 weeks aerobic exercise with BWSTT or FBWTT, patients with knee OA had reduced levels of pain for each groups. Within 3 weeks of the intervention, patients randomized to BWSTT were also to significantly increase their length of stride, speed of walking and distance walked, but these functions did not improve significantly among patients assigned to FBWTT. We conclude that 3 weeks of BWSTT could be beneficial in increasing exercise capacity and walking speed and in ameliorating pain, but may not improve balance functions during every day activities or the general QOL.

\section{References}

1) Fransen $M$ and McConnell S: Exercise for osteoarthritis of the knee. Cochrane Database Syst Rev. 2008, CD004376.

2) Pelland L, Brosseau L, Wells G, Macleay L, Lambert J, Lamothe C, Robinson V and Tugwell P: Efficacy of strengthening exercises for osteoarthritis (part A): meta-analysis. Phys Ther Rev. 2004, 6: 77-108.

3) Richmond J, Hunter D, Irrgang J, Irrgang J, Morgan H, Levy B, Robert M, Lynn S, William C, Robert H, Charles M, Janet L, Kevin M, Anderson S and Mcgowan R: Treatment of osteoarthritis of the knee (nonarthroplasty). J Am Acad Orthop Surg. 2009, 17: 591-600.

4) Ettinger WH Jr, Burns R, Messier SP, Applegate W, Rejeski WJ, Morgan T, Shumaker S, Berry MJ, Toole MO, Monu J and Craven T: A randomized trial comparing aerobic exercise and resistance exercise with a health education program in older adults with knee osteoarthritis. JAMA. 1997, 277: 25-31. 
5) Hootman JM, Macera CA, Ainsworth BE, Martin M, Addy $\mathrm{CL}$ and Blair SN: Association among physical activity level cardiorespiratory fitness and risk of musculoskeletal injury. American Journal of Epidemiology. 2001, 154: 251-258.

6) Dietz, Colombo G and Jensen L: Locomotor activity in spinal man. Lancet. 1994, 344: 1260-1263.

7) Werning A and Muller S: Laufband locomotion with body weight support improved walking in persons with severe spinal cord injuries. Paraplegia. 1992, 30: 229-238.

8) Hesse S, Bertelt C, Jahnke MT, Schaffrin A, Baake P, Malezic $\mathrm{M}$ and Mauritz KH: Treadmill training with partial body weight support compared with physiotherapy in nonambulatory hemiparetic patients. Stroke. 1985, 26: 976-981.

9) Nilsson L, Carlsson J, Danielsson A, Fugl MA, Hellstrom K, Kristensen L, Sjolund B, Sunnerhagen KS and Grimby G: Walking training of patients with hemiparesis at an early stage after stroke: a comparison of walking training on a treadmill with body weight support and walking training on the ground. Clin Rehabil. 2001, 15: 515-527.

10) Visintin M, Barbeau H, Korner N and Mayo N: A new approach to retrain gait in stroke patients through body weight support and treadmill stimulation. Stroke. 1998, 29: 11221128.

11) Yagura $H$, Hatakenaka $M$ and Miyai I: Does therapeutic facilitation add to locomotor outcome of body weight supported treadmill training in nonambulatory patients with stroke? A randomized controlled trial. Arch Phys Med Rehabil. 2006, 87: 529-535.

12) Schindl MR, Forstner C, Ken $H$ and Hesse S: Treadmill training with partial body weight support in nonambulatory patients with cerebral palsy. Arch Phys Med Rehabil. 2000, 81: 301-306.

13) Miyai I, Fujimoto Y, Ueda Y, Yamamoto H, Nozaki S, Saito T and Kang J: Treadmill training with body weight support its effect on Parkinson's disease. Arch Phys Med Rehabil. 2000, 81: 849-852.

14) Miyai I, Fujimoto Y, Yamamoto H, Ueda Y, Saito T, Nozaki $\mathrm{S}$ and Kang J: Long-term effect of body weight-supported treadmill training in Parkinson's disease: A randomized controlled trial. Arch Phys Med Rehabil. 2002, 84: 1370-1373.

15) Ota M, Ohata K, Tateuchi H, Nishimura, J Mori K and Ichihashi N: Immediate Effects of the Body Weight Supported Treadmill Training for the Patient with Orthopedics Diseases. Rigakuryoho Kagaku. 2008, 23: 753-757. (in Japanese)

16) Hesse S, Werner C, Seibel H, Frankenberg SV, Kappel EM, Kirker S and Kading M: Treadmill training with partial body weight support after total hip arthroplasty: a randomized controlled trial. Arch Phys Med Rehabil. 2003, 84: 1767-1773.

17) Fukui N, Yamane $S$, Ishida $S$, Tanaka $K$, Masuda $R$, Tanaka N, Katsuragawa Y and Fukui S: Relationship between radiographic changes and symptoms or physical examination findings in subjects with symptomatic medial knee osteoarthritis: a three-year prospective study. BMC Musculoskeletal Disorders. 2010, 11: 269-279.

18) Tuli SM and Kapoor V: High tibial closing wedge osteotomy for medial compartment osteoarthrosis of knee. Indian J Orthop. 2008, 42: 73-77.

19) Colby SM, Kirkendall DT and Bruzga RF: Electromyo- graphic analysis and energy expenditure of harness supported treadmill walking implications for knee rehabilitation. Gait Posture. 1999, 10: 200-205.

20) American Geriatrics Society Panel on Exercise and Osteoarthritis. Exercise prescription for older adults with osteoarthritis pain: consensus practice recommendations. A supplement to the AGS Clinical Practice Guidelines on the management of chronic pain in older adults. J Am Geriatr Soc. 2001, 49: 808-823.

21) Murray MP: Gait as a total pattern of movement. Am J Phys Med. 1967, 46: 290-333.

22) Duncan PW, Winter DK and Chandler J: Functional reach: a new clinical measure of balance. J gerontol. 1990, 45: 192197.

23) Vellas BJ, Wayne SJ and Romero L: One-leg balance is an important predictor of injurious falls in older persons. J Am Geriatr Soc. 1997, 45: 735-738.

24) Podsiadlo D and Richardson S: The timed "Up and Go": a test of basic functional mobility for frail elderly persons. J Am Geriatr Soc. 1991, 39: 142-148.

25) Butland RJ, Pang J, Gross ER, woodcock AA and Geddes DM: Two-six and 12-minute walking test in respiratory disease. BMJ (Clin Res Ed). 1982, 284: 1607-1608.

26) Martin M, Behan E and Chilleme J: Patient rehabilitation aid that varies treadmill belt speed to match a user's own step cycle based on leg length or step length. United States Paten. 2003, 6645126.

27) Fukuhara S, Bito S, Green J, Hsiao A and Kurokawa K: Translation, adaptation, and validation of the SF-36 Health Survey for use in Japan. Journal of Clinical Epidemiology. 1998, 51: 1037-1044.

28) Doi $T$, Akai M, Fujino K, Iwata $T$, Kurosawa $H$ and Hayashi $\mathrm{K}$ : Effect of home exercise of quadriceps on knee osteoarthritis compared with nonsteroidal anti-inflammatory drugs: a randomized controlled trial. Am J Phys Med Rehabil. 2008, 87: 258-269.

29) Sullivan KJ, Knowlton BJ and Dobkin BH: Step training with body weight support: effect of treadmill speed and practice paradigms on post stroke locomotor recovery. Arch Phys Med Rehabil. 2002, 83: 683-691.

30) Danielsson A and Sunnerhagen KS: Oxygen consumption during treadmill walking with and without body weight support in patients with hemiparesis after stroke and in healthy subjects. Arch Phys Med Rehabil. 2000, 81: 953-997.

31) Kamide N, Shiba $Y$ and Maeda M: Short-term Intervention Including Partial body weight supported treadmill training for a Patient with Progressive Supranuclear Palsy. Journal of Japanese Physical Therapy Association. 2005, 32: 130-134.

32) Okuno J, Tomura S, Yanagi H, Yabushita N, Kim MJ, Seino $\mathrm{S}$, Okura $\mathrm{T}$ and Tanaka K: Evaluation of the association between impaired renal function and physical function among community-dwelling Japanese frail elderly based on the estimated glomerular filtration rate (eGFR). Nihon Ronen Igakkai Zasshi. 2009, 46: 63-70. (in Japanese)

33) Yamada M and Ichihashi N: Predicting the probability of falls in community-dwelling elderly individuals using the trailwalking test. Environ Health Prev Med. 2010, 15: 386-391. 